

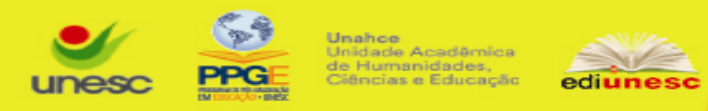

O saber não nos torna melhores nem mais felizes. Mas a educação pode ajudar a nos tornarmos melhores, se não mais felizes, e nos ensinar a assumir a parte prosaica e viver a parte poética de nossas vidas.( Edgar Morin).

O presente artigo trata de partilhar e apresentar experiências interdisciplinares que 0 Grupo de Estudos e Pesquisas em Educação e Imaginário Social (GEPEIS/UFSM), do Grupo de Pesquisas Auto-narrativas de práticas musicais (Narramus/UFSM) e da Associação Civil Piazito Arte e Cultura compartilharam e realizaram no evento IV Encontro Ouvindo Coisas, III Encontro de Educação Musical e Pesquisa (Auto)Biográfica e II Festival Nacional de Cinema Estudantil (CINEST) realizado na Universidade Federal de Santa Maria, no Centro de Educação-UFSM. O evento teve como característica principal o dispositivo de reflexão e escuta dos formatos de práticas educativas, visando as relações intersubjetivas, os intercâmbios e as escutas entre pesquisadores, discentes e docentes.

Tendo em vista que a maioria dos espaços acadêmicos desconsidera os laços afetivos e a singularidade de cada indivíduo, em contrapartida a esse imaginário instituído na universidade de que o currículo caracteriza a pessoa, nosso evento vem ao encontro de possibilitar vivências que valorizam o sujeito além de seu nível de formação, sua profissão ou produção acadêmica, assim, o que se quis alcançar com a proposição do "IV Encontro Ouvindo Coisas, III Encontro de Educação Musical e Pesquisa (Auto)Biográfica e II Festival Nacional de Cinema Estudantil (CINEST)" foi, além da tarefa, do trabalho, da pesquisa em todas as suas dimensões e epistemologias, valorizar os afetos, as qualidades de modo que cada um pudesse colaborar na dinâmica grupal.

Esclarece-se que a marca do evento é oferecer diferentes vivências, podendo elas ser e/ou não formativas, pois tudo depende dos sentidos que os participantes envolvidos atribuem àquilo que vivem. Buscando em Ferry (2004), pode-se dizer que o Encontro Ouvindo Coisas pode ser visto como mediador do processo de formação, entretanto, cada pessoa é responsável pela sua formação, em buscar maneiras de "ponerse en forma" promovendo a constituição dos processos de autonomia do 
sujeito que forma e é formado nos processos educacionais.

Com a realização do primeiro evento em 2010, que na ocasião intitulava-se "I Encontro Ouvindo Coisas: Instituindo outras formas de estar juntos", o segundo realizado em 2011 "Il Encontro Ouvindo Coisas: Experimentações sob a ótica do imaginário" e o terceiro em 2013 "III Encontro Ouvindo Coisas - Imagens de 20 Anos: Imaginário, Memória E Formação" entendemos que é possível instituir outras formas de estar juntos mais significativas e intensas, no qual os participantes sintam-se dispostos para a escuta, para o envolvimento e para a participação coletiva e no cuidado de si.

Assim sendo, o que intencionamos é oferecer novas maneiras de produção de conhecimentos a partir de experimentações sensíveis que tomem como ponto de partida o mundo vivido, nas questões ligadas ao imaginário e à dimensão do coletivo nos diferentes espaços e formações sociais. Para isto, toma-se a estética como forma de expressão para integrar ciência, educação, arte, música, fotografia, cinema, filosofia, poesia e imaginário. Enfim, entendendo que todas as expressões artísticas precisam ser valorizadas e articuladas interdisciplinarmente para a constituição do conhecimento e do cuidado de si.

Lembra-se que em eventos anteriores o Narramus, convidou egressos do curso de Música a compartilhar suas experiências e debatê-las entre si. Além disso, os egressos tiveram um espaço de formação com a presença de professores palestrantes, e um último momento de troca de experiências musicais através da preparação de um recital de encerramento.

O GEPEIS, nas três edições anteriores do Encontro Ouvindo Coisas, sempre priorizou pela aproximação dos sentidos e representações dos atuais modos/modelos de (auto) formação, buscando através das experiências estéticas e da valorização do sensível na academia, instituir outras formas de estar juntos, formar-se, e compartilhar experiências de saberes e afetos.

O CINEST vem em sua segunda edição de festival incentivando a produção artística audiovisual no âmbito escolar, tendo como público-alvo alunos do $5^{\circ}$ ao $9^{\circ}$ ano do ensino fundamental e do ensino médio das escolas públicas e particulares. 0 Festival tem o intuito de atingir o ambiente escolar e envolver professores e 
familiares na proposta de movimentação cultural.

No ano de 2014, unindo essas três propostas, Narramus, GEPEIS e CINEST pensou-se um Encontro conjunto para dois dias, 10 e 11 de Outubro, tendo como resultados esperados, possibilitar a comunicação de pesquisas e relatos de experiências diversas na área, com palestrantes, mediadores, artistas a serem confirmados nesta proposta interdisciplinar de extensão universitária a fim de valorizar o compartilhamento e o diálogo na/com a universidade e a comunidade.

Caminhos Metodológicos: trajetos e movimentos percorridos nesta proposta pedagógica

Por acreditarmos na ideia de grupos como dispositivos de formação, trazemos Souto (2007) que diz que através deles é possível uma aproximação mais consistente e precisa das significações imaginárias dos participantes, tendo em vista que o evento foi uma estratégia criada para potencializar significados que permitem analisar situações, transformando-as em novas aprendizagens. Enfim, tudo que pode provocar, tocar, fazer pensar, é um dispositivo de formação. Ainda, compreendemos que são as produções coletivas que consolidam redes de investigações, tendo como subsídios os temas do Imaginário, das Narrativas Docentes e da Memória como meios para possibilitar a participação de todos na construção de saberes no âmbito subjetivo e profissional.

De acordo com Castilho (2004, p. 60-61), "[...] o apoio do grupo é o reflexo da necessidade real de se ajudar o outro, de se criar um elo dentro do grupo, ou seja, a busca da interação e da coesão grupal.". Através desse apoio visível entre os participantes, surge o sentimento de "pertencer a" (lbid, p. 61) o qual se faz necessário para que o grupo alcance a homeostase. A homeostase é a busca do equilíbrio interno do grupo, sendo esse um sistema aberto em contínua interação e movimento. Para a manutenção do sistema, o grupo elabora seus próprios mecanismos de defesa, buscando equilibrar os interesses pessoais e coletivos com a influência externa do meio social (CASTILHO, 2004).

No intuito de apresentar a experiência do IV Encontro Ouvindo Coisas, III Encontro 
de Educação Musical e Pesquisa (Auto) Biográfica e II Festival Nacional de Cinema Estudantil (CINEST), tendo como pressuposto que ele se articulou na intenção de um dispositivo para se pensar o imaginário social, formação do professor na perspectiva interdisciplinar com distintas e variadas formas de expressar 0 conhecimento na relação com o mundo vivido.

Neste sentido, articulou-se dinâmicas de trabalho em grupo, a fim de potencializar espaços de reflexão de (auto)formação aos participantes, foram realizados rodas de conversação, intervenções artísticas como dança, música, contação de histórias, teatro, exposição fotográfica e de esculturas, lançamento de livros e Festival de Cinema Estudantil. Também, pensou-se o evento como dispositivo de reflexão e formação, onde a partilha de saberes interdisciplinares, os intercâmbios e as escutas entre os pesquisadores, discentes e a comunidade escolar foram valorizados, assim como, quanto o espaço de encontro singular dentro da universidade.

O evento aconteceu nos dias 10 e 11 de outubro de 2014. No primeiro dia do IV Encontro Ouvindo Coisas, contamos com a presença de professores da Universidade Federal de Santa Maria, durante a abertura os mesmos realizaram performance artística, nos remetendo a memória, explorando os sentidos como o ato de ouvir e sentir. A referida performance teve como estratégia vendar os olhos dos participantes e deslocá-los para um ambiente onde havia copos plásticos espalhados pelo chão e barbantes coloridos que formavam uma teia na altura mediana do expectador. Esse ao realizar a experiência foi convidado a fazer parte de uma sinfonia musical, tendo seus sentidos provocados. Logo foi realizado a provocação intitulada "Sons da vida, autobiografando histórias" pela prof. ${ }^{a}$ Valeska Fortes de Oliveira (UFSM), coordenadora do GEPEIS, grupo promotor do projetoevento, em parceria com a prof. ${ }^{a}$ Ana Lúcia de Marques e Louro-Hettwer (UFSM) coordenadora do - Grupo de Pesquisas Auto-narrativas de práticas musicais Narramus. Este momento foi marcado pelo início das discussões acerca do imaginário, formação, narrativa, (auto)biografia e música, o qual é o tema gerador do evento, onde:

Imaginação, imaginário, imagens, representações simbólicas, míticas - essas expressões foram durante muito tempo banidas do 


\section{CRIAR EDUCAÇÃO}

Revista do Programa de Pós-Graduação em Educação - UNESC

\section{更}

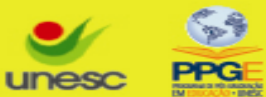

pensamento considerado científico e legítimo por caracterizarem um campo "perigoso", no qual a preocupação com a constatação ficaria prejudicada (OLIVEIRA, 2005, p. 69).

Após, tivemos a provocação "Poéticas e políticas da escuta: na arte, na escola, na vida, com a fala dos professores Glauber Resende (UFRJ) e Marcos Villella Pereira (PUC/RS).

Em seguida aconteceram as oficinas: da prof ${ }^{\underline{a}}$ Camila Borges, prof ${ }^{\underline{a}}$ Cândice Lorenzoni (UFSM) e profa Andriza Kemel Zanella (UERG), intitulado o "Corpo e voz na docência: O Sensível na vida do professor". Esta visou problematizar a docência a partir de experiências concretas, envolvendo o corpo e a voz do professor. Buscou-se com este direcionamento, uma abordagem voltada à educação sensível na formação de professores, enfocando a história de vida, o imaginário, a corporeidade, a vocalidade e a criatividade a partir de um trabalho focado no devaneio e na reinvenção de si no contexto em que vivemos/atuamos.

"O cinema de cada um" foi outra oficina, ministrada pelos professores Marilia Hartmann, Noeli Weschenfelder e Marilene Leal Farenzena, que trabalharam com a metodologia autobiográfica com enfoque nas singularidades do cinema na vida e na formação docente, tendo como objetivo de problematizar o cinema enquanto experiência estética propulsora de imaginários.

Já a oficina "Memórias e aprendizagens na flauta doce" - ministrada pelos professores Ana Louro (UFSM), Vanessa Weber (UFSM) e Zelmielen Adornes de Souza (UFSM), solicitaram aos participantes narrarem as suas histórias de vida relacionada ao instrumento flauta doce.

A oficina "Memórias musicais e ensino de música" ministrada pelos professores Juliane Riboli Corrêa, Jéssica de Almeida e Laura Cordeiro realizaram reflexões da prática de repertórios e atividades musicais a partir da perspectiva das memórias e narrativas de si, questionando de que maneira estas memórias se manifestam na constituição dos professores e em suas escolhas pedagógicas.

A oficina "Improvisação musical" ministrada pelo prof. Adolfo Almeida Júnior oportunizou atividades musicais para todos que se dispuseram a interagir através dos sons.

A parceira com o CINEST proporcionou a oficina "Cinema na escola" - ministrados

Criar Educação, Criciúma, v. 6, nº1, julho/novembro 2016.-PPGE - UNESC 


\section{CRIAR EDUCAÇÃO}

Revista do Programa de Pós-Graduação em Educação - UNESC

(19)

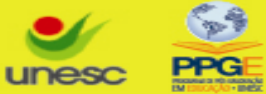

ediunesc

pelos participantes da ONG Piazito: Mariângela Cardoso, Daniel Paim e a profáa Cláudia Nunes, objetivou-se sensibilizar professores dos Anos Iniciais e Finais de todas as redes de ensino e de diferentes áreas que é possível através da Sétima Arte como potência de criar, aprender e reaprender a vida dentro da escola.

A oficina "Fazer silêncio e cuidar de si" ministrada pelo prof. Marcos Villela Pereira (PUC/RS), propôs exercícios de leitura e escuta de poemas e textos clássicos sobre "como se pensa" e "pensar sobre o que se pensa", a partir da leitura/escuta e do silêncio que sobrevém. Pensar em si, falar de si e cuidar de si.

Após, ocorreu o café cultural, momento de socialização entre os participantes do evento e apreciação das provocações permanentes, como: Mostra de audiovisuais da profá . Ana lara Deus e a profa Andréa Narvaes (UERGS), juntamente teve a exibição da premiação do II Festival Nacional de Cinema Estudantil.

Nessas provocações permanentes estavam os expositores Wagner Borges com suas Xilogravura e Granito; a fotógrafa Stephanie Chauvin com a mostra "Trabalhadores do Sol"; a instalação "Interferindo no que parece pronto" de Lisiane Dutra Lopes (UFSM); mostra da Práticas Artísticas com os alunos da Escola Estadual Humberto de Campos, e "Retratos da Boca do Monte" de Alessandra Jungs de Almeida (UFSM). Houve também, as apresentações de expressões culturais com peças teatrais de grupos colaboradores do evento.

Durante os dois dias de evento ocupamos parte da tarde com as rodas de conversas, que se deu a partir das apresentações de trabalhos a partir de eixos temáticos. Esses eixos foram: I. Narrativas e música na Educação Básica, mediado pela profa - Tamar Genz Gaulke; II. Experiências de professores e música(s), mediado pelo prof. Gérson Luís Werlang, III. Imaginário, Cinema e Formação, mediado pela prof ${ }^{a}$ Ana lara Deus e o prof. Lisandro Moura, IV. Imaginário, Cuidado de Si e Arte, mediado pelo prof. Deonir Kurek e a prof ${ }^{a}$ Janine Bochi do Amaral.

Os grupos inscritos em suas respectivas salas sociabilizaram suas produções de cada eixo temático, após a apresentação, dialogaram sobre os trabalhos apresentados.

Dessa forma, visou-se dar visibilidade do evento IV Encontro Ouvindo Coisas, III Encontro de Educação Musical e Pesquisa (Auto)Biográfica e II Festival Nacional de

Criar Educação, Criciúma, v. 6, nำ1, julho/novembro 2016.- PPGE - UNESC 
Cinema Estudantil (CINEST) que buscou consolidar redes de investigação constituída a partir dos temas do Imaginário, Memória, Cinema, Formação Docente e Pesquisa (Auto)Biográfica.

As formas de intervenção e escolhas de ações metodológicas desse evento, tiveram a intenção de contribuir na constituição de territórios que permitam experimentar e promover a potência de encontros, deslocamentos com a universidade, os saberes e as questões do mundo vivido.

Nos diálogos e ações das experiências e encontros do IV Encontro Ouvindo Coisas, III Encontro de Educação Musical e Pesquisa (Auto)Biográfica e II Festival Nacional de Cinema Estudantil (CINEST), tem-se como entendimento que essa experiência promoveu possibilidades de novos e potentes encontros da relação do saber e dos afetos entre a universidade e a comunidade, visto que, para alcançar nossos objetivos, quais sejam: organizar vivências e espaços de discussões que fossem significativos e que possibilitassem diferentes encontros com o saber; valorizando as experiências sensíveis atravessadas pelas teorias em cada um; dando ênfase ao trabalho compartilhado; consolidando uma rede de investigação constituída a partir dos temas do Imaginário, Cinema e Pesquisa (Auto)Biográfica, da Formação Docente, obteve-se narrativas e reflexões dos participantes que, analisaram o evento como tendo proporcionado a reflexão sobre o deslocamento de verdades e comportamentos instituídos na relação dos afetos e saberes.

O Encontro promoveu o intercâmbio de investigação com diversos grupos de pesquisas do estado, do país e de outros países, e a comunidade mostrou-se como formas potentes de se interagir com o conhecimento, dando sentido as suas vivências individuais e coletivas.

Para atingir tais objetivos, constatou-se que a elaboração desde provocações enfatizando diferentes temáticas, mini-cursos, rodas de discussão, entre outras vivências e experimentações para os dois dias de realização do evento, foram pertinente, sendo que, optamos para que as atividades fossem desenvolvidas nos turnos da manhã, tarde e noite na Universidade Federal de Santa Maria, tendo como local o Centro de Educação-UFSM.

Lembrando, que é pertinente salientar que durante todos os dias do evento tivemos

Criar Educação, Criciúma, v. 6, ํo1, julho/novembro 2016.- PPGE - UNESC 


\section{CRIAR EDUCAÇÃO}

Revista do Programa de Pós-Graduação em Educação - UNESC

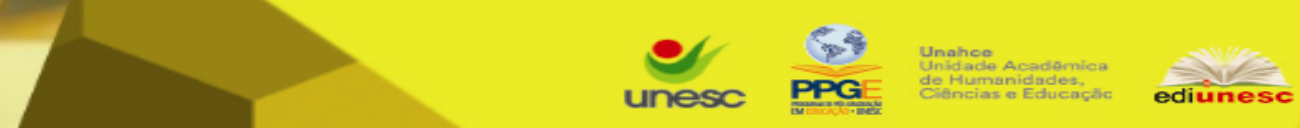

a participação de músicos, pessoas envolvidas com o cinema, dança, teatro e expositores que provocaram o público com fotografias, esculturas, com intervenções e poesia, o que envolveu ainda mais os encontros interdisciplinares com os participantes.

Neste sentido, entendemos que o evento IV Encontro Ouvindo Coisas, III Encontro de Educação Musical e Pesquisa (Auto)Biográfica e II Festival Nacional de Cinema Estudantil (CINEST) se caracteriza como inovador, devido à sua forma instigadora de apresentação dos trabalhos, de atividades na forma de interação entre o público e os propositores de discussões. No evento não houve palestras, mas falas, imagens, música, dança, teatro, entre tantas outras intervenções que se caracterizaram por provocações, as quais instigaram e mexeram com os imaginários instituídos e instituintes dos participantes acerca dos processos de formação docente, formação do sujeito.

No que se refere às mudanças, as visões sobre os eventos acadêmicos foram (res)significadas através do evento que trouxe novas propostas de formação, a partir de outras formas de estar juntos e de as experimentações sensíveis sob a ótica do imaginário social. Este é um dos resultados mais positivos que pudemos perceber na reação dos participantes, os quais relataram que este estar junto possibilitou maior socialização, deslocamento, troca de perspectivas sobre o conhecimento e as práticas pedagógicas, de ideias e saberes, em outras palavras, mais potência nos processos e movimentos de ensino e aprendizagem e os afetos.

Considerações sobre a formação de professores e a comunidade escolar nas atividades realizadas

A formação de professores carece de maneiras criativas para a socialização de seus estudos e pesquisas. Posto isto, a realização desse evento, que já está em sua quarta edição, se instituiu como dispositivo de reflexão e ação sobre os formatos que os eventos na área educacional tem proporcionado no meio acadêmico.

Desse modo, acreditamos que fomos capazes de instituir novas formas de estar juntos, com um formato de evento onde os participantes tiveram o espaço da escuta 


\section{CRIAR EDUCAÇÃO}

Revista do Programa de Pós-Graduação em Educação - UNESC
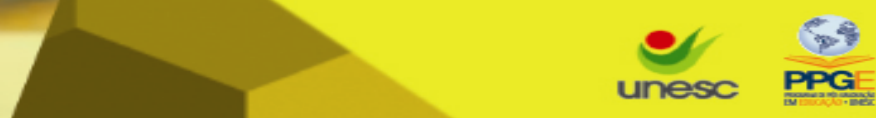

e a (res)significação de aprendizagens e afetos, produzindo novas formas de encontros interdisciplinares e de relações intersubjetivas com o conhecimento.

Assim, inferimos que este evento contribui significativamente para todos que participaram, tendo em vista a potencialização de territórios que permitam experimentar novas formas de relação entre afetos e o saber na/com a universidade. Além disso, estimulou para que em novembro deste ano, tenhamos o V Encontro Ouvindo Coisas. 


\section{CRIAR EDUCAÇÃO}

Revista do Programa de Pós-Graduação em Educação - UNESC
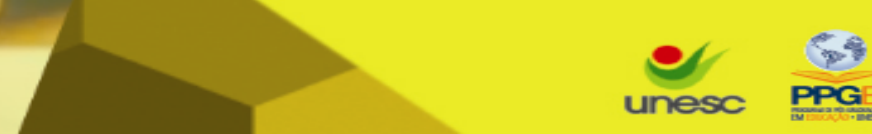

\section{REFERÊNCIAS}

CASTORIADIS, Cornelius. A instituição imaginária da sociedade. Rio de Janeiro: Paz e Terra, 1982.

O mundo fragmentado: as encruzilhadas do labirinto. Vol III. Rio de Janeiro: $\overline{\mathrm{Paz}}$ e Terra, 1992.

Figuras do Pensável: as encruzilhadas do labirinto. Volume VI. Rio de Janeiro: Civilização Brasileira, 2004.

FERRY, Gilles. Pedagogia de la formación. Buenos Aires: Centro de Publicaciones Educativas y Material Didáctico, 2004.

FOUCAULT, Michel. Tecnologías Del Yo Y Otros Textos Afines. Paidós Ibérica. I.C.E. de la Universidad Autónoma de Barcelona, 1995.

A hermenêutica do sujeito. São Paulo: Martins Fontes, 2010.

GOHN, Daniel Marcondes. Auto Aprendizagem musical: alternativas tecnológicas. São Paulo: Annablue/Fapsep, 2003.

HERMANN, Nadja. Autocriação e horizonte comum: ensaios sobre educação éticoestética. ljuí: Editora Unijuí, 2010.

MORIN, Edgar. O CINEMA ou O HOMEM IMAGINÁRIO: ensaio de Antropologia. SP: Editora É Realizações, 2014.

Spinoza. Ética. Trad, Tomás Tadeu, BH: Editora Autêntica, 2013.

SOUTO, M. El carácter de "artifício" Del dispositivo pedagógico em la formación para el trabajo. Buenos Aires: Facultad de Filosofia y Letras, 2007.

TIBURI, Márcia. Filosofia Prática: ética, vida cotidiana, vida virtual. RJ: Editora Record, 2014. 